\title{
PRESSURE LOSSES IN A NETWORK OF TRIANGULAR MICROCHANNELS
}

\author{
Mariusz Niklas ${ }^{\mathrm{a}}$, mariuszniklas@,o2.p1 \\ M. Favre-Marinet ${ }^{\mathrm{a}}, \underline{\text { Michel.Favre-Marinet@hmg.inpg.fr }}$ \\ a) presently at Institute of Thermal Machinery, University of Czestochowa, \\ Al Armii Krajowej 21, 42200 Czestochowa Poland \\ b) Laboratoire des Ecoulements Géophysiques et Industriels \\ CNRS-UJF-INPG, 1025 rue de la Piscine, BP 53 X, 38041, Grenoble Cedex, France
}

\begin{abstract}
The flow characteristics of a network of parallel microchannels (hydraulic diameter: $110 \mu \mathrm{m}$ ) were investigated both experimentally and numerically in the present work. The cross-section of the micro-channels was triangular for further application to micro heat pipes. Measurements of the pressure drop across the microchannels network showed a dramatic increase of the pressure losses and a departure from the law of fully developed flow as soon as the Reynolds number of the flow exceeded about 10 . Numerical computations of the flow were performed by using the classical laws of hydrodynamics in order to explain this surprizing result. They showed a good agreement with the experimental results, which suggests that there are no size effects at the length scale used in the experiments. Moreover, the mechanisms responsible of the large pressure drop in the high-range of Reynolds number are identified by the numerical analysis. They correspond to extra head losses due to separation in several parts of the test cell.
\end{abstract}

\section{Nomenclature}

$\mathrm{D}_{\mathrm{h}}$ hydraulic diameter,

$f$ Fanning friction factor,

L microchannel length

p pressure,

$\mathrm{p}^{*}$ normalized pressure

Po Poiseuille number, $\quad=f \mathrm{Re}$

$\mathrm{Re}=\frac{\rho \mathrm{VD}_{\mathrm{h}}}{\mu} \quad$ Reynolds number

$\mathrm{V}$ average bulk velocity,
Greek symbols

$\rho$ density,

$\mu$ dynamic viscosity,

$\mathrm{m}^{3} \cdot \mathrm{s}^{-1}$

$\mathrm{kg} \cdot \mathrm{m}^{-1} \cdot \mathrm{s}^{-1}$

\section{OBJECTIVES}

This study is connected to a joined project of several laboratories, aimed at designing new heat pipes of very small size (typical length scale, $200 \mu \mathrm{m}$ ). The laws of hydrodynamics are questionable at these very small length scales and many papers have underlined the uncertainties in applying the laws of macroscale flows to microsystems (for example, Flockhart and Dhariwal, 1998; for a review, see Guo and Li, 2002). Since hydrodynamics, in particular the resisting wall friction, play an important role in the working principles of heat pipes, it was decided to investigate singlephase isothermal flow across microchannels of triangular cross-section identical to those which will be used for heatpipe operation. The present study considers the flow across a network of 55 parallel microchannels, which was connected to a closed-loop circuit. An experimental investigation of the pressure drop across the network was complemented by numerical computations of the flow in order to interpret the data and to detect possible size effects on the results. 


\section{EXPERIMENTS}

\section{Experimental facility}

A network of 55 parallel microchannels was etched in a silicon wafer by a wet anisotropic technique. The channels were $215 \mu \mathrm{m}$ in maximal width, $150 \mu \mathrm{m}$ in height (length $\mathrm{L}$ $=18.4 \mathrm{~mm}$, hydraulic diameter $\left.\mathrm{D}_{\mathrm{h}}=110 \mu \mathrm{m}\right)$. They were connected to an upstream distributor channel and a downstream collector channel of identical rectangular crosssection (width $800 \mu \mathrm{m}$, height $188 \mu \mathrm{m}$ ). The network was covered with a silicon wafer by direct wafer bonding. Two holes were managed in the cover in order to connect the network of microchannels to a demineralized water circuit. The configuration of the channels network is depicted in Fig. 1 and the dimensions are given in Table 1.

Tab. 1. Geometrical parameters of the cell

\begin{tabular}{|c|c|c|}
\hline \multirow{4}{*}{$\begin{array}{l}\text { Triangular } \\
\text { microchannels }\end{array}$} & Microchannel width & $\begin{array}{c}215 \mu \mathrm{m} \pm 10 \\
\mu \mathrm{m}\end{array}$ \\
\hline & Microchannel height & $150 \mu \mathrm{m} \pm 5 \mu \mathrm{m}$ \\
\hline & Hydraulic diameter & $D_{h}=110 \mu \mathrm{m}$ \\
\hline & Microchannel length & $\mathrm{L}=18.4 \mathrm{~mm}$ \\
\hline \multirow{3}{*}{$\begin{array}{l}\text { Distribution } \\
\text { channel } \\
\text { Collector } \\
\text { channel }\end{array}$} & Channel height & $\mathrm{h}_{\mathrm{dc}}=188 \mu \mathrm{m}$ \\
\hline & Channel width & $\mathrm{a}_{\mathrm{dc}}=800 \mu \mathrm{m}$ \\
\hline & Channel length & $\mathrm{L}_{\mathrm{dc}}=20 \mathrm{~mm}$ \\
\hline \multirow{3}{*}{$\begin{array}{l}\text { Main inlet and } \\
\text { outlet channels }\end{array}$} & Channel height & $\mathrm{h}_{\mathrm{dc}}=188 \mu \mathrm{m}$ \\
\hline & Channel width & $\mathrm{a}_{\mathrm{dc}}=835 \mu \mathrm{m}$ \\
\hline & Channel length & $\mathrm{L}_{\mathrm{dc}}=1.5 \mathrm{~mm}$ \\
\hline
\end{tabular}

The pressure drop $\Delta \mathrm{p}$ across the complete system of channels was determined by piezo resistive strain gauge transmitters placed upstream/downstream of the tested cell (full scale: $10^{6} \mathrm{~N} \cdot \mathrm{m}^{-2}$, accuracy: $10^{4} \mathrm{~N} \cdot \mathrm{m}^{-2}$ ) or by a differential gauge (full scale: $10^{4} \mathrm{~N} \cdot \mathrm{m}^{-2}$, accuracy: $10^{2} \mathrm{~N} \cdot \mathrm{m}^{-}$ ${ }^{2}$ ). The flow rate was measured by precision weighing or by a high-accuracy flowmeter (full scale: $0.251 \mathrm{mn}^{-1}$, accuracy: $0.0011 \mathrm{mn}^{-1}$ ), for the highest flow rates. The range of Reynolds number investigated was [1-700] (Re is based on the average bulk velocity $\mathrm{V}$ across the channels and the hydraulic diameter of one channel). The pressure drop $\Delta \mathrm{p}$ is related to the Fanning friction factor by

$$
f=\frac{\Delta p}{2 \rho \mathrm{V}^{2}} \frac{\mathrm{D}_{\mathrm{h}}}{\mathrm{L}}
$$

\section{Experimental results}

Measurements of the pressure drop across the system of microchannels are reported on Fig. 2, which shows a dramatic increase of the flow resistance compared to fully developed conditions ( $\mathrm{Po}=13.3$ ) when the Reynolds number is higher than about 10. Experimental uncertainties
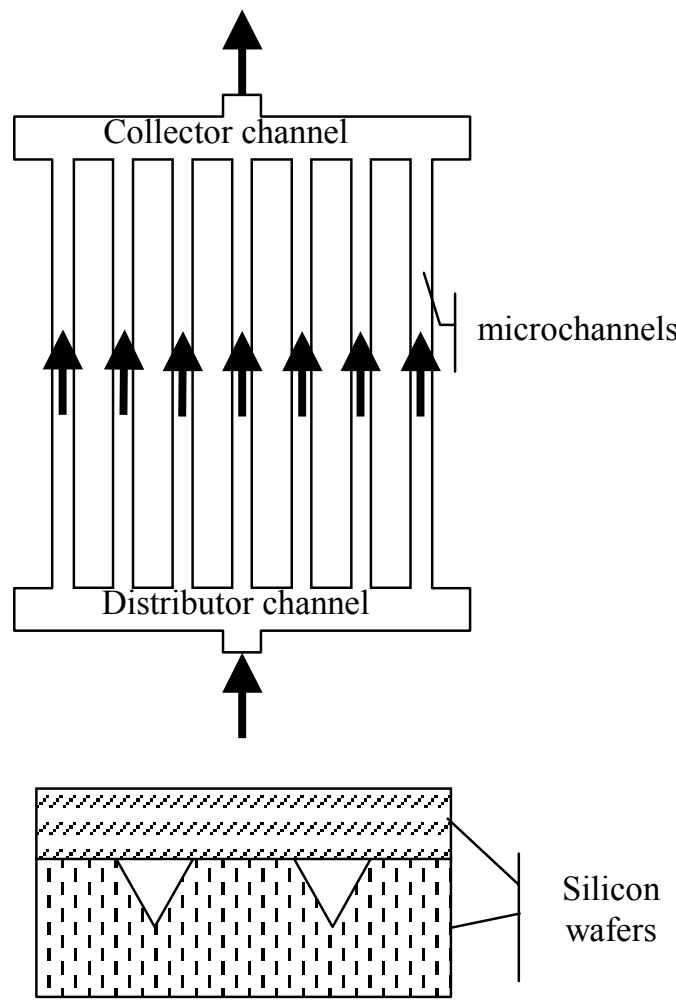

Figure 1. System of parallel triangular channels on the silicon plate

were estimated and reported on the same graph. Previous experimental works on flows in microchannels (Peng et al., 1994) showed that the laminar-turbulent transition takes place for lower Reynolds numbers (about 700) than in the case of conventional channels. However, the large increase of pressure losses observed in the experiments occurs at Reynolds numbers much lower than these transitional values. Numerical studies of a complete system of triangular channels were then undertaken in order to investigate the origin of the flow resistance in these microchannels.

\section{NUMERICAL COMPUTATIONS}

\section{Numerical scheme}

The numerical computations of the flow were achieved by using the commercial code Fluent 5.4. The basic equations were the usual continuity and Navier-Stokes equations. The flow regime was assumed laminar. The equations were discretized using second order scheme with the second order upwinding method. The segregated solver was applied with the SIMPLEC pressure correction methods. Meshing was performed by using Gambit 1.3. The solution was treated as converged when the level of residuals was lower than $10^{-5}$. This was obtained after 


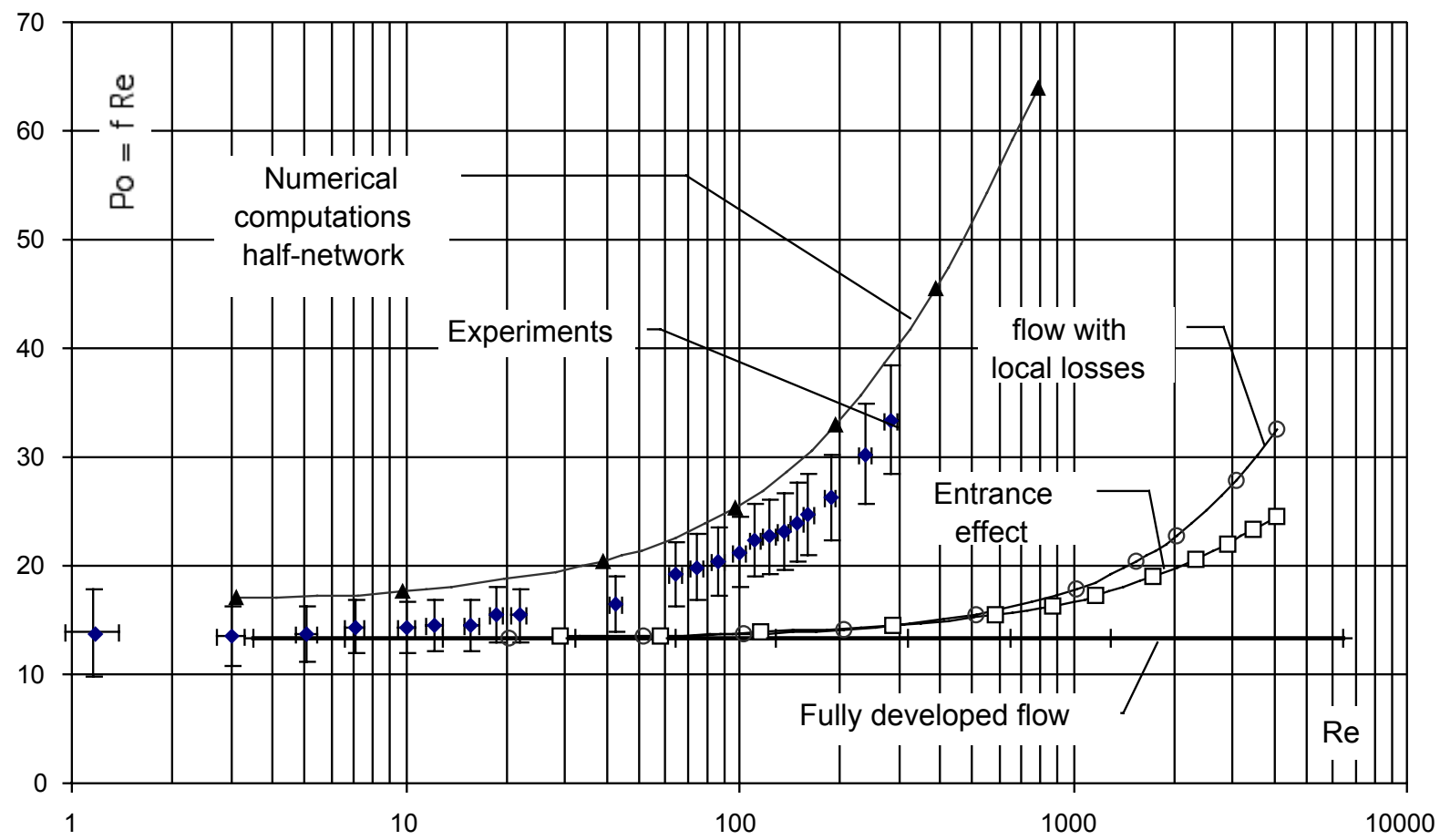

Figure 2. Pressure drop across the system of microchannels

approximately 1000 iterations. Grid independence was carefully checked on the solution. The calculations were performed for 300,000, 600,000 and 900,000 elements. The comparisons showed that the highest differences between these three cases were lower than $3 \%$.

\section{Numerical results.}

Single channel flow. Preliminary calculations were performed for a single channel in three steps with the following assumptions:

fully developed flow in a triangular microchannel

flow with entrance effects in a triangular microchannel

flow with local losses caused by a sudden change of the cross section at the inlet of a microchannel.

Streamwise-periodic conditions over the microchannel length were assumed for the velocity field in the first case. The computations of the fully developed flow provided excellent agreement with the results of the literature $(\mathrm{Po}=$ 13.3, Bejan, 1995). The velocity was assumed uniform at the channel inlet and the development of boundary layers was computed in the second case. The last case considered a channel of rectangular cross-section (height $188 \mu \mathrm{m}$, width $215 \mu \mathrm{m}$ ) followed by a microchannel with a triangular crosssection of the same maximal width. For the two latter cases, particular grid refinement was achieved near the microchannel inlet, where boundary layers are developing.
Figure 2 compares the numerical results to the experimental data. It clearly shows that the entrance effect and the local losses due to a reduction of section have little influence on the flow resistance and cannot explain the discrepancies with the experimental results, even in the range of high Re numbers.

Flow through the system of channels. In a next step, the computational domain was similar to the real network of channels but was reduced to one half of the whole system owing to the symmetry of the configuration (Fig. 3). The grid consisted of 300,000 cells for the half-network. As mentioned before, additional computations were achieved with 600,000 and 900,000 cells and showed negligible differences in the results. The numerical results follow closely the tendency of the experiments (Fig. 2). The pressure drop is slightly overestimated by the computations. The differences may be due to the uncertainties in the numerical simulations, but also to unwanted phenomena in the experiments, such as the possible presence of air trapped in the corners of the triangular cross-section. Guo and $\mathrm{Li}$ (2002) suggested that this phenomenon could give rise to a reduction of the actual cross section and to subsequent local acceleration of the flow. They also claimed that the first effect should be the prevailing phenomenon, giving rise to a reduction in the measured friction factor. This could account partly for the differences between the present experimental and numerical results. 


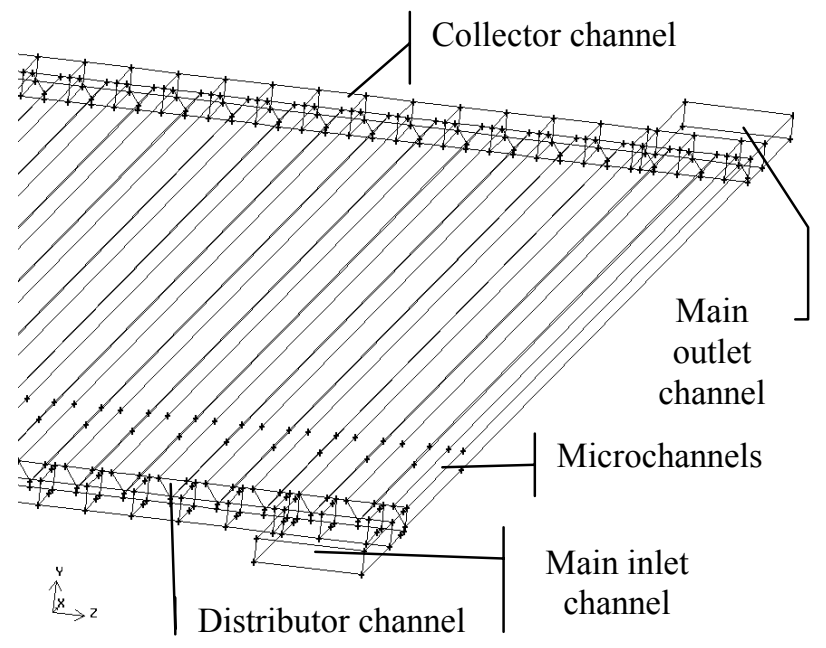

Figure 3. Computational domain of the complete model

According to numerical and experimental accuracies, the present results suggest that no size effects are present in the flow investigated, which was characterized by a length scale of $110 \mu \mathrm{m}$. The same result was found by Gao et al. $(2000 \mathrm{a}, \mathrm{b})$ in a single microchannel of high-span rectangular cross-section.

Analysis of the pressure and velocity fields. Careful analyses of the flow parameters in this complex system of channels show that there are some other sources of high pressure losses in addition to those in the microchannels.

For the following presentation of results, the pressure and velocity fields are considered in the plane located at $\mathrm{y}=$ $100 \mu \mathrm{m}$ above the bottom of the microchannels. The pressure field is illustrated by Figures 4, 5, 6, 7 for a typical value of the Reynolds number $(\mathrm{Re}=390)$.

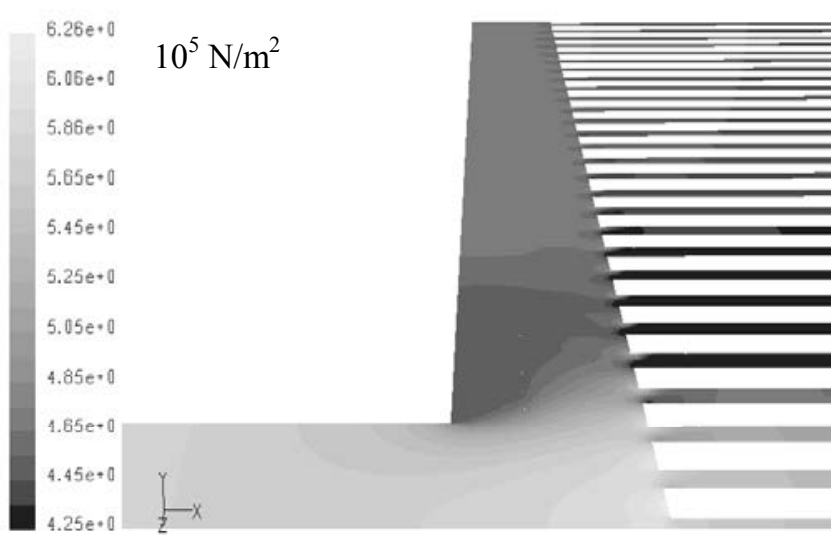

Figure 6. Contours of static pressure in the inlet region. $\mathrm{Re}=390$

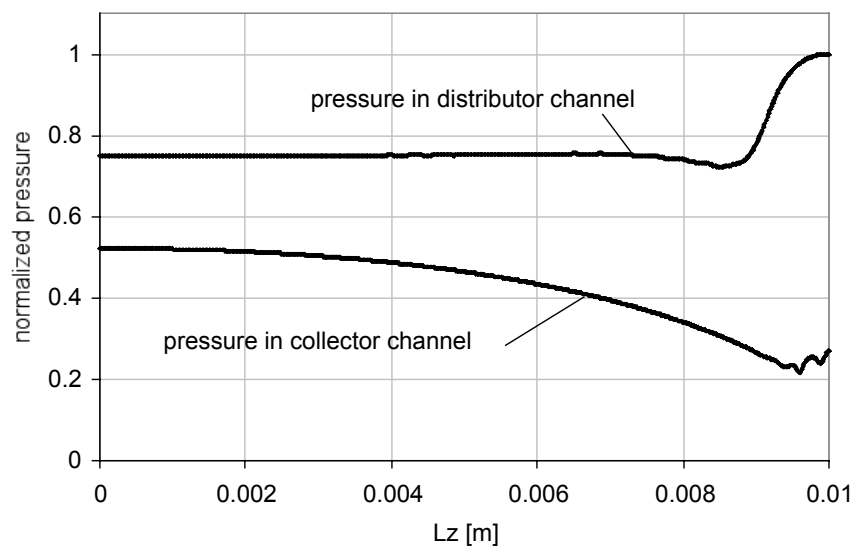

Figure 4. Pressure in the distributor and collector channels for $\mathrm{Re}=390$

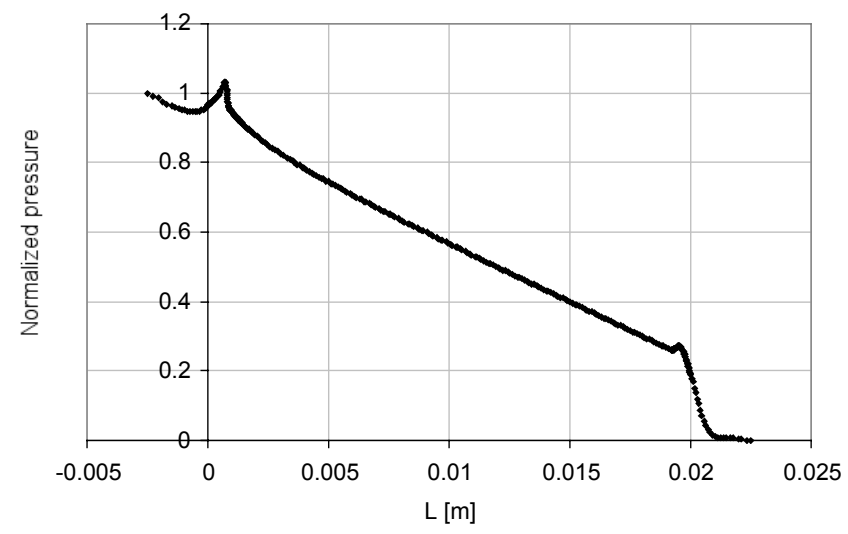

Figure 5. Pressure on the centre line of the system of channels. $\mathrm{Re}=390$

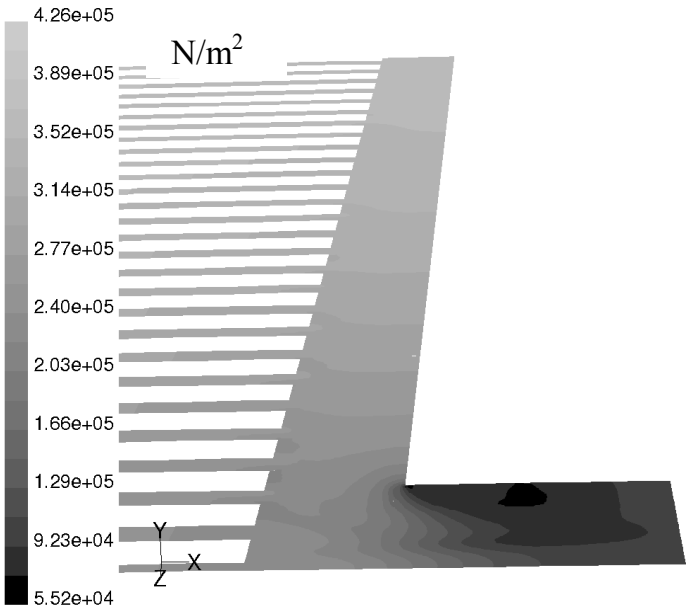

Figure 7. Contours of static pressure in the outlet region. $\mathrm{Re}=390$ 

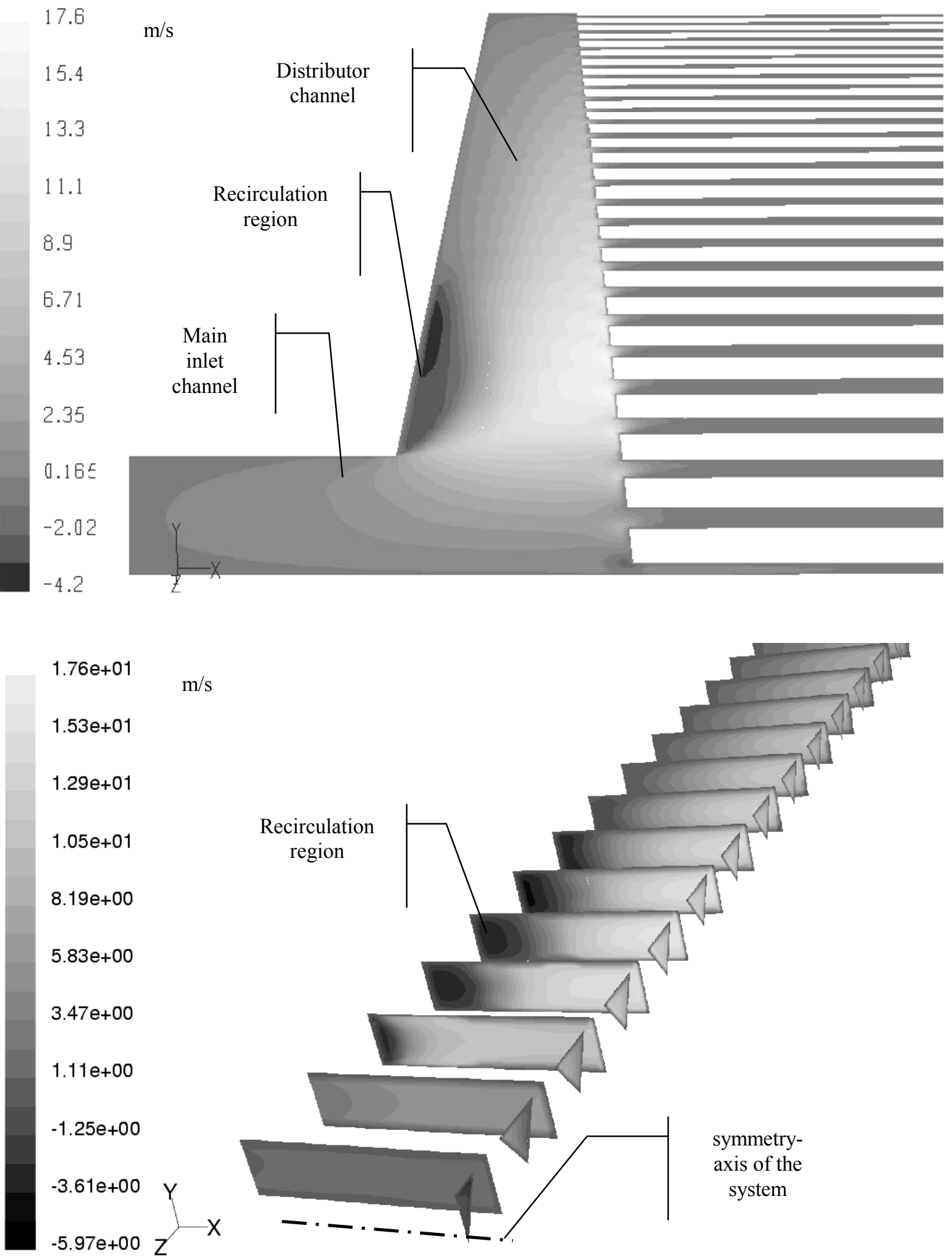

Figure 8. Contours of $\mathrm{z}$ - velocity component in the inlet region (top) and in cross-sections of the distributor channel (bottom). $\mathrm{Re}=390$ 
The pressure is normalized in Figures 4 and 5 by

$$
\mathrm{p}^{*}=\frac{\mathrm{p}-\mathrm{p}_{\mathrm{ref}}}{\mathrm{p}_{\max }-\mathrm{p}_{\mathrm{ref}}}
$$

where $p_{\max }$ is the pressure at the distributor channel inlet and $\mathrm{p}_{\text {ref }}$ is the pressure at the exit section of the main outlet channel $\left(p_{\text {ref }}=101,000 \mathrm{~N} \mathrm{~m}^{-2}\right)$.

The pressure along the distributor and collector channels is plotted in Fig. 4, which shows the high pressure drop at the inlet of the distribution channel (the axis of symmetry of the channels system is located at $\mathrm{z}=10 \mathrm{~mm}$ ). Figure 5 displays the pressure distribution on the axis of symmetry of the system. The left part of the curve corresponds to the inlet main channel $(\mathrm{x}<0)$ and to the distribution channel. The triangular microchannel starts at $\mathrm{x}=0.8 \mathrm{~mm}$ and ends at $\mathrm{x}=19.2 \mathrm{~mm}$. The collector channel and the main outlet channel correspond to $\mathrm{x}>19.2 \mathrm{~mm}$, symmetrically from the inlet part. The linear pressure distribution from $\mathrm{x}=0.8 \mathrm{~mm}$ to $\mathrm{x}=19.2 \mathrm{~mm}$ illustrates the regular pressure drop along the microchannel located in the plane of symmetry. The explanation of the pressure distribution of Fig. 4 is clearly visible in Fig. 8, which displays contours of the z-velocity component in the inlet region. The bottom part of the figure shows these contours in several cross-sections of the distributor channel. The z-direction is perpendicular to the symmetry-axis of the system so that the flow along the distributor channel is highlighted in Fig. 8. The sudden change in the flow direction at the end of the main inlet channel gives rise to a strong separation at the beginning of the distributor channel. This reverse flow causes a significant reduction of the distributor channel cross-section and consequently to a high pressure drop in this region. Sufficiently far from the region of reversed flow, the pressure is practically constant (see also Fig. 6).

Figure 9 displays contours of $\mathrm{x}$-velocity component in the outlet region. The $\mathrm{x}$-axis corresponds to the outlet channel direction. The flow pattern in the collector channel is quite different from that of the distributor channel (Fig. 8). This region is dominated by the merging of jets outflowing from the triangular microchannels. These jets are responsible of intense mixing with the flow in the collector channel and of subsequent continuous head losses in this region. These head losses cannot be simply avoided because they are related to the sudden change of section at the end of the triangular microchannels (Fig. 4). As in the distributor channel, a region of separation is found at the beginning of the outlet main channel and contributes to the total pressure drop.

Figure 10 shows the distribution of bulk velocities in the

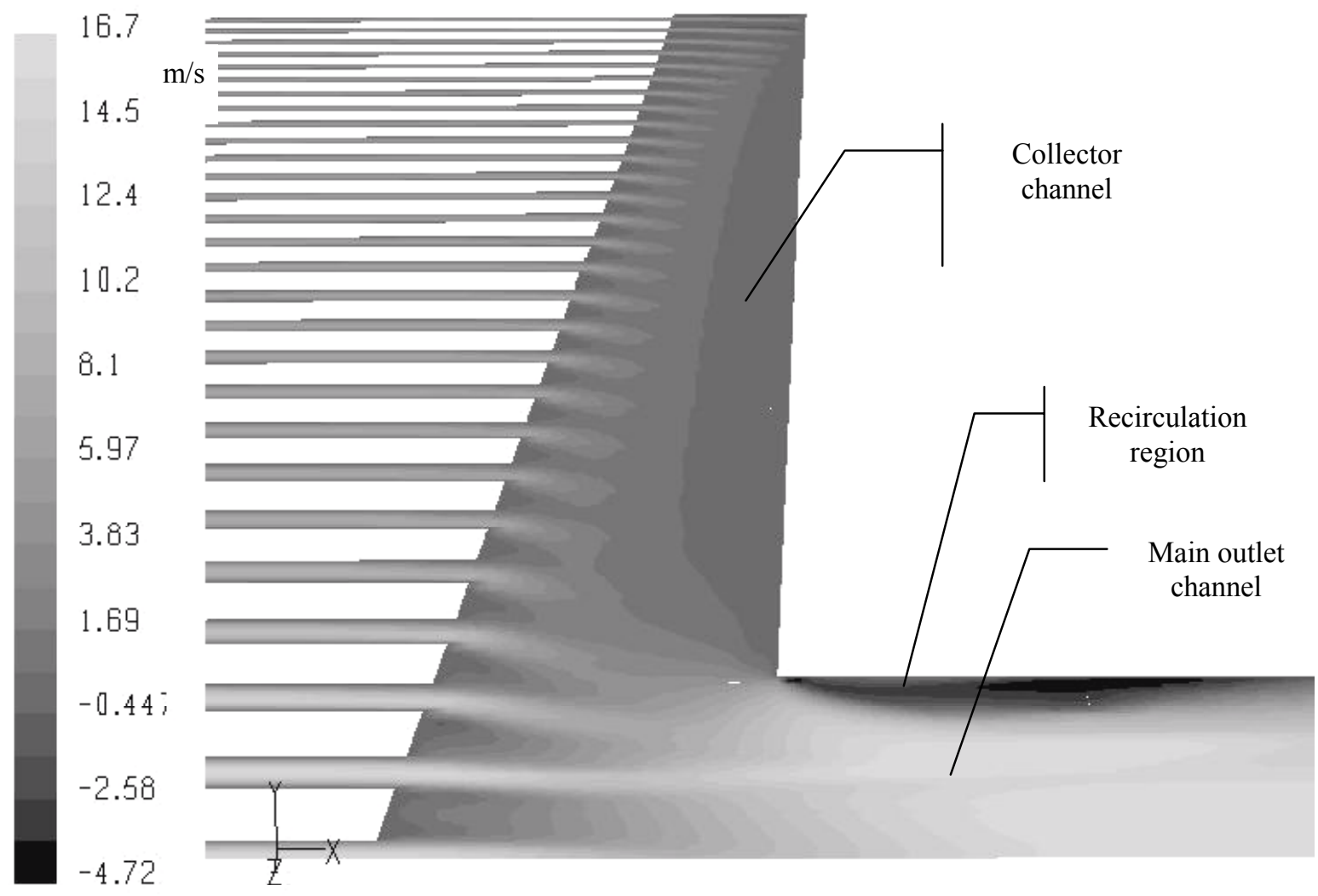

Figure 9. Contours of $x$ - velocity component in the outflow region. $R e=390$ 


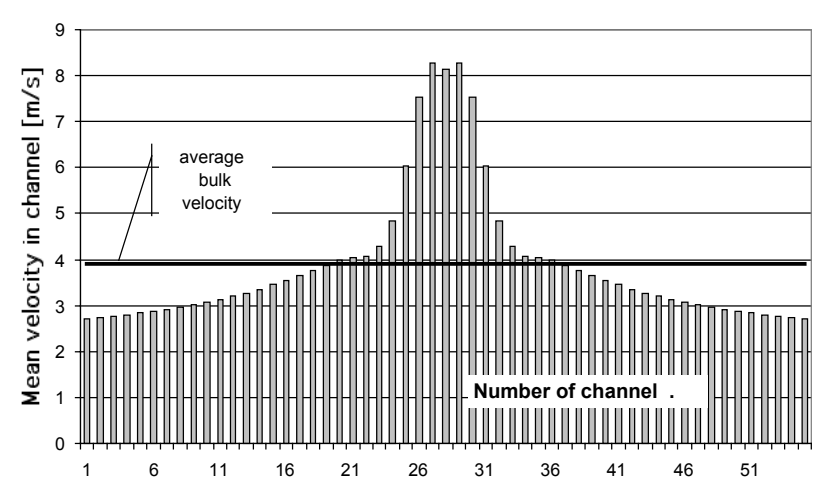

Figure 10. Distribution of bulk velocities in the system of microchannels. $\mathrm{Re}=390$

system of parallel microchannels. The results of the computations were completed by symmetry principle to depict the complete system. The mean velocities vary significantly from channel to channel, according to the pressure differences displayed in Fig. 4. The highest velocities and mass flow rates are obviously observed near the axis of symmetry of the system of channels. It may be worth noting that the ratio of the highest to smallest velocities along the system is slightly Reynolds dependent (it is equal to 2.5 for $\operatorname{Re}=195$ and to 3 for $\operatorname{Re}=390$ ).

Figure 11 shows the contribution of the various phenomena to the total pressure losses as a function of the Reynolds number. In this figure, we have separated the different sources of pressure losses in the flow. The curves correspond to the various assumptions used for the computations and reproduce the results associated to each assumption: The bottom part corresponds to the fully developed flow all along the microchannels. Additional

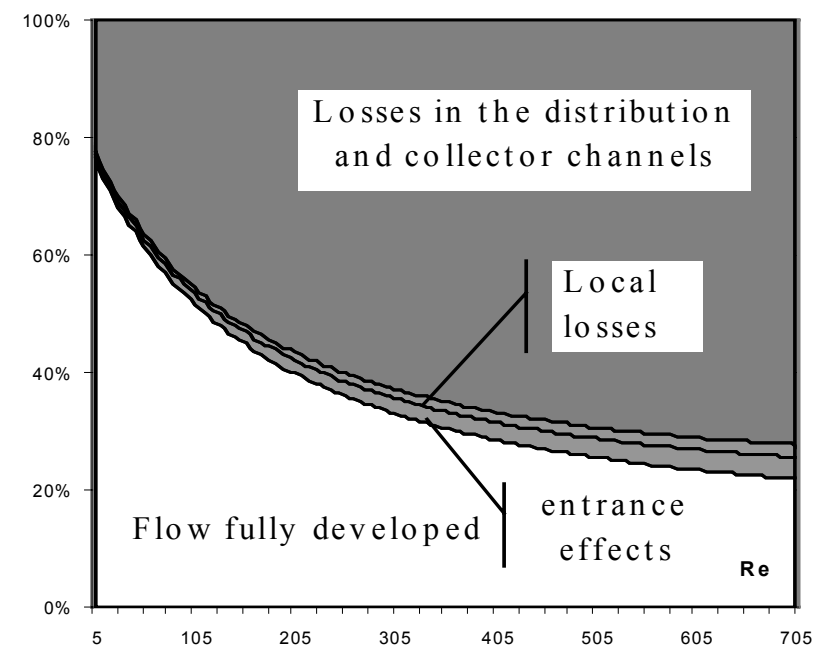

Figure 11. Contribution to total pressure losses versus Re number losses due to entrance effects and losses associated to the sudden change of section at the beginning of the microchannels correspond to the two next areas. Finally, the upper part of the figure corresponds to the sum of the pressure losses in the main inlet/outlet channels and in the distributor/collector. This figure demonstrates that two main phenomena have a significant contribution to the total losses in the system. The regular losses in the microchannels account for a very large part of the total losses at low values of the Reynolds number ( $80 \%$ for $\operatorname{Re}=5$ ). This contribution obviously decreases when the Reynolds number is increased $(20 \%$ for $\operatorname{Re}=700)$. This may be understood since the regular pressure drop in a microchannel is proportional to the flow rate whereas the pressure losses due to separation and mixing are likely to be proportional to the squared flow rate. As can be seen in Fig. 11, the pressure drop is caused mainly by losses in the distributor and collector channels for the high range of Reynolds numbers. For Re higher than 200, the pressure drop caused by friction in the microchannels is lower than half of the total losses.

This analysis of the pressure field shows that optimization of the flow in microchannels systems should be concentrated in the proper design of the distribution and collector channels.

\section{CONCLUSION}

The present study considered the flow in a complex network of microchannels with triangular cross-section. Comparison of the numerical results to the experimental data shows that the pressure drop across the network of microchannels may be reasonably predicted by numerical computations based on the classical laws of hydraulics. As a result, it may be concluded that size effects are negligible on hydrodynamics in triangular microchannels with a hydraulic diameter of $110 \mu \mathrm{m}$.

This research also underlines the care which must be taken in interpreting pressure measurements during the study of microchannel flows. Estimation of the pressure drop across one microchannel requires a careful separation of pressure variations in the region of interest and in the parts of the system, which are used to connect the microchannel to an external hydraulic circuit.

Finally, it should also be stressed that careful design of a complex network of microchannels, as in micro heat exchangers, is necessary to avoid excessive pressure losses in the system.

\section{ACKNOWLEDGEMENTS}

This research was supported by the Region RhôneAlpes. The authors would like to gratefully acknowledge the Socrates program for partly support of the stay of Marius Niklas in Grenoble. They also wish to thank Nicolas Mazellier for performing the experiments. 


\section{REFERENCES}

Bejan A., Convection Heat Transfer $2^{\text {nd }}$ Ed., John Wiley \& Sons, New York, USA (1995).

Flockhart S. M., Dhariwal R. S., Experimental and numerical investigation into the flow characteristics of channels etched in $<100>$ silicon, J. of Fluid Engineering, 120 (1998), 291-295

Gao P., Le Person S., Favre-Marinet M., Scale effects on Hydrodynamics and Heat Transfer in two-dimensional mini and microchannels, Int. J. of Thermal Sciences, 41, (2002a) 1017-1027.
Gao P., Le Person S., Favre-Marinet M., Hydrodynamics and Heat Transfer in two-dimensional microchannels, $12^{\text {th }}$ Int. Heat Transfer Conf (2002b), Grenoble, France

Guo Z. Y., Li Z. X., Size effect on microscale singlephase flow and heat transfer, $12^{\text {th }}$ Int. Heat Transfer Conf (2002), Grenoble, France

Peng X. F., Peterson G. P., Wang B. X., Frictional flow characteristics of water flowing through rectangular microchannels, Experimental Heat Transfer 7(4) (1994), 249-264 